\title{
SENSIBILIDADE DO Colletotrichum gloeosporioides DO MARACUJAZEIRO A ÓLEOS ESSENCIAIS
}

Sensitivity of Colletotrichum gloeosporioides in passion fruit to essential oils Desafios

Sensibilidad de Colletotrichum gloeosporioides en pasión a los aceites esenciales

\section{Ana Rosa de Figueiredo ${ }^{* 1}$, Leirson Rodrigues da Silva ${ }^{1}$, Lilia Aparecida} Salgado de Morais ${ }^{2}$

${ }^{1}$ Laboratório de Ecologia Microbiana, Curso de Pós-Graduação em Ciência, Tecnologia e Inovação Agropecuária, Universidade Federal Rural do Rio de Janeiro (UFRRJ), Seropédica, Brasil.

${ }^{2}$ Centro de Recursos Biológicos Johanna Döbereiner, Embrapa Agroecologia, Seropédica, Brasil.

* Correspondência: Centro de Recursos Biológicos Johanna Döbereiner, Rodovia BR-465, Km 7, Seropédica, RJ, Brasil. CEP: 23897-970.e-mail ana.agroambiente@gmail.com.

\section{RESUMO}

Colletotrichum gloeosporioides é o agente etiológico de diversas doenças em frutíferas mundialmente. No maracujá, o fungo causa a antracnose, doença que ataca toda a planta, principalmente frutos maduros. No tocante à segurança alimentar e ambiental, o manejo desse patógeno deve incluir apenas produtos naturais, de baixo risco ao equilíbrio dos ecossistemas. Nesse contexto, o objetivo do presente estudo foi verificar a sensibilidade in vitro de $C$. gloeosporioides a óleos essenciais. A atividade antimicrobiana dos óleos essenciais foi avaliada pelo método de disco-difusão e microdiluição em caldo. Determinou-se a concentração inibitória mínima (CIM) e a concentração fungicida mínima (CFM) para cada óleo essencial. A CIM ficou entre 160 a $5 \mu \mathrm{L} / \mathrm{mL}$ nos diferentes óleos essenciais, sendo o de basilicão e canela-cássia os que alcançaram as menores concentrações. Os óleos essenciais de melaleuca, citronela, menta-arvensis e tomilho-branco demonstraram ação fungistática. Ótimos resultados foram obtidos na determinação da CFM para os óleos essenciais de canela-cássia $(10 \mu \mathrm{L} / \mathrm{mL})$, gengibre $(80 \mu \mathrm{L} / \mathrm{mL})$, basilicão $(160$ $\mu \mathrm{L} / \mathrm{mL})$ e laranja-doce $(160 \mu \mathrm{L} / \mathrm{mL})$.

Palavras-chave: Antracnose, atividade antimicrobiana, óleo essencial.

\section{ABSTRACT}

Colletotrichum gloeosporioides is the etiologic agent of several diseases in fruit trees worldwide. In passion fruit the fungus causes anthracnose disease that attacks the all plant parts, especially ripe fruits. With regard to food and environmental security, the management of this pathogen should include only natural products of low risk to the ecosystems balance. In this context, the objective of the present study was to verify the in vitro sensitivity of $C$. gloeosporioides to essential oils. The antimicrobial activity of essential oils was screened using the disk diffusion method and broth micro dilution. The minimum inhibitory concentration (CIM) and the minimum fungicidal concentration (CFM) were determined for each essential oil. The CIM was from 160 to $5 \mu \mathrm{L} / \mathrm{mL}$ in the different essential oils, with basil and cinnamon cassia being those that reached the lowest concentrations. The essential oils of tea tree, citronella, mint arvensis and thyme showed fungistatic action. Excellent results were obtained in determining the CFM for cinnamon cassia essential oils $(10 \mu \mathrm{L} / \mathrm{mL})$, ginger $(80 \mu \mathrm{L} / \mathrm{mL})$, basil $(160 \mu \mathrm{L} / \mathrm{mL})$ and sweet orange $(160 \mu \mathrm{L} / \mathrm{mL})$.

Keywords: Anthracnose, antimicrobial activity, essential oil. 


\section{RESUMEN}

Colletotrichum gloeosporioides es el agente etiológico de varias enfermedades en árboles frutales en todo el mundo. En la fruta de la pasión, el hongo causa antracnosis, una enfermedad que ataca a toda la planta, especialmente a los frutos maduros. En lo que respecta a la seguridade alimentaria y ambiental, el manejo de este patógeno debe incluir únicamente productos naturales, de bajo riesgo para el equilibrio de los ecossistemas. En este contexto, el objetivo del presente estudio fue verificar la sensibilidad in vitro de C. gloeosporioides a aceites esenciales. La actividad antimicrobiana de los aceites esenciales se evaluó mediante el método de difusión en disco y microdilución en caldo. Se determinó la concentración mínima inhibitoria (CIM) y la concentración mínima de fungicida (CFM)para cada aceite esenciale. La CIM estuvo entre 160 a $5 \mu \mathrm{L} / \mathrm{mL}$ en los diferentes aceites esenciales, siendo albahaca y canela-casia los que alcanzaron las concentraciones más bajas.Los aceites esenciales de árbol de té, citronela, menta arvensis y tomillo blanco mostraron acción fungistática. Se obtuvieron excelentes resultados en la determinación de CFM para los aceites esenciales de canela-casia $(10 \mu \mathrm{L} / \mathrm{mL})$, jengibre $(80 \mu \mathrm{L} / \mathrm{mL})$, basílica $(160$ $\mu \mathrm{L} / \mathrm{mL})$ y naranja dulce $(160 \mu \mathrm{L} / \mathrm{mL})$. Descriptores: Antracnosis, actividad antimicrobiana, aceite esenciale.

\section{INTRODUÇÃO}

O Brasil é atualmente o maior produtor e consumidor mundial do maracujá (Passiflora edulis sims), que pode ser cultivado em praticamente todas as regiões e estados no país, apresentando grande importância econômica e social, com geração de empregos no campo, no setor de venda de insumos, nas agroindústrias e nas cidades. Ademais, é importante na constituição de renda ao longo do ano, principalmente para micro e pequenos fruticultores, especialmente aqueles ligados à agricultura familiar (FALEIRO e JUNQUEIRA, 2016).

Com a expansão dos cultivos, doenças ocasionadas por patógenos são frequentes. De acordo com Agrios (2005), as doenças de plantas são responsáveis por perdas significativas nas culturas de importância econômica, da ordem de $14,1 \%$ do total de perdas, mais 6 a 12\% são devido às doenças em póscolheita, principalmente nos países tropicais em desenvolvimento. O gênero Colletotrichum representa um dos mais importantes grupos de patógenos de plantas em todo o mundo, os quais são responsáveis pela ocorrência de doenças em uma grande variedade de espécies de plantas, tanto lenhosas quanto herbáceas, especialmente as frutíferas em pós-colheita (CANNON et al., 2012). De acordo com Junqueira et al. (2003) as perdas em matéria fresca causadas pelo Colletotrichum gloeosporioides em maracujazeiro- doce variam de 9,78 a $22,06 \%$, sendo as maiores perdas, quando o armazenamento não ocorre em câmara fria.

No maracujá-amarelo, a antracnose é considerada a mais importante doença em pós colheita, ocorrendo, principalmente, em frutos desenvolvidos e sob condições de alta umidade relativa do ar e temperaturas elevadas $\left(26^{\circ} \mathrm{C}\right.$ a $\left.28^{\circ} \mathrm{C}\right)$, o que contribui para a diminuição do tempo de conservação dos frutos. Além disso, toda a parte aérea das plantas pode ser afetada pela ação parasitária do fitopatógeno (FISCHER et al., 2005). A antracnose é causada pelo fungo $C$. gloeosporioides cuja forma perfeita é o teleomorfo Glomerella cingulata. O fitopatógeno sobrevive em restos culturais, sendo disseminado por respingos de água, insetos, sementes, implementos agrícolas e mudas contaminadas. Seus danos são mais expressivos em plantios adultos, geralmente após o primeiro pico de safra, chegando a provocar secas de ramos e morte de plantas (JUNQUEIRA e GUIMARÃES, 2007).

No tocante ao aumento da qualidade e segurança alimentar relativa ao consumo de frutas, a Anvisa (2019) implementou o monitoramento do Programa de Avaliação de Resíduos de Agrotóxicos em Alimentos (PARA), que ocorre anualmente. Ainda assim, tem sido detectado não conformidades em amostras de frutas, resíduos de ingredientes ativos 
altamente prejudiciais à saúde. Foram consideradas insatisfatórias $23 \%$ das amostras analisadas, destacando-se o ingrediente ativo carbofurano, proibido no país por meio da Resolução da Diretoria Colegiada - RDC no 185/2017. Além disso, outros compostos acima do limite mínimo de resíduo ou agrotóxicos não autorizados foram detectados, o que traz indícios de que os ingredientes aprovados ainda não atendem às necessidades das culturas (BRASIL, 2017).

Nesse aspecto, destaca-se que a importância do controle de doenças com o uso de fontes naturais sustentáveis, que promovam a segurança alimentar e nutricional, com substâncias mais eficazes e menos tóxicas ao homem e ao meio ambiente, em substituição aos produtos químicos sintéticos (SHARMA et al. 2017).

Atualmente, os óleos essenciais, produtos naturais originados por meio do metabolismo secundário das plantas possuem atividade antifúngica com grande potencial de uso no controle de fitopatógenos (GAHUKAR, 2018). Suas propriedades antimicrobianas são em função de sua composição química, seus compostos aromáticos voláteis (MOUTASSEM, et al. 2019).

Considerando-se a pertinência do tema, testouse in vitro a sensibilidade de C. gloeosporioides a óleos essenciais, na busca de um factível agente biofungicida vegetal, em vista de uma demanda por produtos agrícolas naturais no controle de fitopatógenos.

\section{MATERIAL E MÉTODOS}

Os óleos essenciais (marca comercial Ferquima) das espécies Ocimum basilicum, Zingiber officinale, Citrus sinensis, Cinnamomum cassia, Melaleuca alternifolia, Cymbopogon winterianus, Mentha arvensis e Thymus vulgaris foram testados in vitro contra C. gloeosporioides.
Os mesmos foram analisados por cromatografia gasosa acoplada à espectrômetro de massas (CG-EM Shimadzu, QP 5050, coluna capilar DB-5 - $30 \mathrm{~m}$ x $0.25 \mathrm{~mm}$ de diâmetro interno x $0.25 \mu \mathrm{m}$ de espessura), na programação de $60-240{ }^{\circ} \mathrm{C}\left(3{ }^{\circ} \mathrm{C} /\right.$ min). O gás carreador utilizado foi o hélio. As temperaturas do injetor e do detector foram 240 e 230 ${ }^{\circ} \mathrm{C}$ respectivamente. A identificação da composição química dos óleos essenciais foi realizada a partir da comparação de seus espectros de massa e valores de índice de Kovats (IK) com compostos descritos na literatura (ADAMS, 2007). Os resultados das análises cromatográficas estão apresentados na tabela 1, assim como a forma de obtenção e o nome comum para cada óleo essencial utilizado nas análises. Para a realização dos bioensaios, cada óleo essencial foi diluído separadamente em DMSO a $10 \%$ e Tween 20 a $0,8 \%$. Como controle positivo, foi utilizado o fungicida tiofanato metílico 1.000 ppm e como controle negativo, foi utilizado o solvente DMSO $10 \%$ e Tween 20 a $0,8 \%$.

Os frutos de maracujá com sintomas de antracnose foram obtidos por coletas realizadas conforme Chaves et al. (1973). A cultura estava sob sistema convencional, em um pomar comercial de maracujá localizado no município de Paty do Alferes, Região Metropolitana do Estado do Rio de Janeiro com nas coordenadas geográficas a $22^{\circ} 25^{\prime}$ de latitude sul e $43^{\circ} 25^{\prime}$ oeste de longitude, a 610 metros de altitude. $\mathrm{O}$ fungo foi isolado pelo método direto e recuperado em meio de cultura batata-dextrose-ágar (BDA) e ágarágua a partir de lesões nos frutos (CHAVES et al., 1973; ALFENAS e MAFIA, 2007). Sua identificação foi por meio de microscopia e chaves sistemáticas, baseando-se em critérios morfológicos de identificação (BARNETT e HUNTER, 1972; DOMSCH et al., 1980). Para os ensaios, a suspensão fúngica foi ajustada em solução salina estéril a $0,9 \%$ para turbidez padrão 


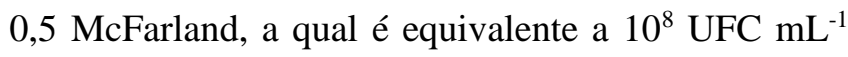

(JEHL et al., 2018).

Tabela 1. Óleos essenciais e seus constituintes químicos majoritários, conforme análises cromatográficas realizadas.

\begin{tabular}{|c|c|c|}
\hline Óleo essencial (obtenção) & $\begin{array}{l}\text { Nome } \\
\text { comum }\end{array}$ & Constituintes químicos majoritários (\% Área) \\
\hline $\begin{array}{l}\text { Ocimum basilicum } \\
\text { (destilação a vapor das folhas) }\end{array}$ & Basilicão & $\begin{array}{l}\text { Linalol }(21,76) \text {; } 1.8 \text {-cineol }(15,60) \text {; cânfora }(11,86) \text {; eugenol } \\
(11,31) \text {; geraniol }(7,52) \text {; neral }(4,35)\end{array}$ \\
\hline $\begin{array}{l}\text { Zingiber officinale } \\
\text { (destilação a vapor da raiz) }\end{array}$ & Gengibre & Geraniol $(20,90)$; neral $(14) ; 1.8$-cineol $(10,85)$; canfeno $(4,35)$ \\
\hline $\begin{array}{l}\text { Citrus sinensis } \\
\text { (prensagem a frio da casca dos frutos) }\end{array}$ & $\begin{array}{l}\text { Laranja- } \\
\text { doce }\end{array}$ & Limoneno $(76,20)$; linalol $(8,92) ; \alpha$-pineno $(2,9)$ \\
\hline $\begin{array}{l}\text { Cinnamomum cassia } \\
\text { (destilação a vapor das folhas, talos e casca) }\end{array}$ & $\begin{array}{l}\text { Canela- } \\
\text { cássia }\end{array}$ & (E)- Cinamaldeído $(93,8) ; \alpha$-terpineol $(1,72) ; 1.8$-cineol $(1,26)$ \\
\hline $\begin{array}{l}\text { Melaleuca alternifólia } \\
\text { (destilação a vapor das folhas) }\end{array}$ & Melaleuca & $\begin{array}{l}\text { Terpinen-4-ol }(37,3) ; \gamma \text {-terpineno }(19,2) ; \alpha \text {-terpineno }(8,53) \text {; } \\
\text { limoneno }(7,53) ; 1.8 \text {-cineol }(6,39)\end{array}$ \\
\hline $\begin{array}{l}\text { Cymbopogon winterianus } \\
\text { (destilação a vapor das folhas) }\end{array}$ & Citronela & $\begin{array}{l}\text { Geraniol }(33,7) \text {; citronelal }(23,2) \text {; citronelol }(5,18) \text {; limoneno } \\
(1,29)\end{array}$ \\
\hline $\begin{array}{l}\text { Mentha arvensis } \\
\text { (destilação a vapor das folhas) }\end{array}$ & $\begin{array}{l}\text { Menta- } \\
\text { arvensis }\end{array}$ & $\begin{array}{l}\text { Mentol }(90,2) ; \text { limoneno }(1,26) ; \alpha \text {-terpineno }(0,84) \text {; beta-pineno } \\
(0,95)\end{array}$ \\
\hline $\begin{array}{l}\text { Thymus vulgaris } \\
\text { (destilação a vapor das folhas e flores) }\end{array}$ & $\begin{array}{l}\text { Tomilho- } \\
\text { branco }\end{array}$ & $\begin{array}{l}\text { Timol }(41,2) ; \text { para-cimeno }(21,9) ; \alpha \text {-terpineno }(5,68) ; \gamma \text {-terpineno } \\
(4,72) ;\end{array}$ \\
\hline
\end{tabular}

Nos bioensaios para detecção de atividade antimicrobiana foi utilizado o método de disco-difusão seguindo os protocolos Clinical Laboratory Standard Institute (CSLI), com modificações. A suspensão fúngica foi inoculada por toda a superfície, em placas de Petri de $9 \mathrm{~cm}$ de diâmetro com meio de cultura BDA. Os discos de papel-filtro inoculados com os tratamentos de óleos essenciais, $10 \mu \mathrm{L}$ da diluição $320 \mu \mathrm{L} / \mathrm{mL}$ e os controles foram dispostos de forma equidistantes em cada placa de Petri inoculada. Para evitar a evaporação, as placas foram embrulhadas em papel filme. Após incubação, em câmara incubadora BOD (Biochemical Oxygen Demand) a $27^{\circ} \mathrm{C}$ por $24 \mathrm{~h}$, os diâmetros dos halos de inibição (DHI) foram mensurados por meio de um paquímetro digital e os valores expressos em milímetros. No teste, a verificação da presença ou não de halo de inibição, caracteriza o microrganismo, como resistente ou sensível ao tratamento, conforme CSLI (2012).

A concentração inibitória mínima (CIM) na qual o crescimento do microrganismo é inibido em poços foi realizada pelo método de microdiluição em caldo. No qual foram utilizadas microplacas com 96 poços de fundo redondo, em triplicata. Os poços na placa receberam os tratamentos: $100 \mu \mathrm{L}$ de meio de cultura batata-dextrose duplamente concentrado contendo $10 \%$ da suspensão fúngica e $100 \mu \mathrm{L}$ de óleo essencial de cada tratamento no poço $1 \mathrm{~A}$, sendo repassada alíquota de $100 \mu \mathrm{L}$ para o poço seguinte e assim por diante (microdiluição seriada: 320; 160; 80; 40; 20; 10 e $5 \mu \mathrm{L} / \mathrm{mL})$. O controle de crescimento foi com DMSO (10\%) e Tween 20 a 0,8\% para confirmar a atividade restrita aos produtos. As microplacas foram vedadas com parafilme $\mathrm{M}$ para evitar perdas por evaporação quando no momento da incubação, feita em 
incubadora BOD a uma temperatura de $27^{\circ} \mathrm{C}$ a 48 horas (CLSI, 2012).

A CIM foi determinada pela presença ou não de crescimento visual. $O$ tratamento que inibe completamente o crescimento microbiano no poço é estabelecido como a menor concentração capaz de inibir visualmente o desenvolvimento do microrganismo (CSLI, 2012). Os ensaios foram feitos em triplicata e os resultados expressos pela média aritmética das concentrações inibitórias mínimas obtidas nos três ensaios.

As amostras negativadas no teste da CIM foram semeadas, em duplicata, em batata-dextrose-ágar para a determinação da concentração fungicida mínima (CFM). Após incubação por 72 h em câmara incubadora BOD a $28{ }^{\circ} \mathrm{C}$, as leituras foram efetuadas, sendo considerada a CFM, a menor concentração do óleo essencial que não apresentou crescimento no subcultivo (PEREIRA et al., 2011; ESPINELINGROFF et al., 2002).

\section{RESULTADOS E DISCUSSÃO}

O fitopatógeno foi isolado a partir de frutos maduros, onde foi possível visualizar a presença de sinais nas lesões, como pequenas pontuações com frutificações do fungo (Figura 1). Conforme Fischer et al. (2005), nas áreas afetadas com lesões, quando em condições favoráveis ao desenvolvimento da doença, os sinais do patógeno são facilmente visíveis na forma de pontuações, mais ou menos concêntricas e verificam-se manchas deprimidas de coloração escura que afetam a polpa, muitas vezes apresentam-se na forma de podridão mole e provocando queda nos frutos.

Para checar a atividade antimicrobiana vários métodos têm sido utilizados. Conforme Balouiri et al. (2016) o método de disco-difusão e diluição em caldo são bastante conhecidos, por isso foram adotados neste estudo. O fungo C. gloeosporioides apresentou-se sensível a todos os óleos essenciais testados no presente estudo, onde foi possível determinar a CIM para cada óleo essencial e a CFM, para os óleos essenciais que demonstraram ação fungicida para esse fitopatógeno, conforme apresentado na tabela 2 .

Figura 1. Lesões e sinais do fungo Colletotrichum gloeosporioides em maracujá. A. Lesões; B. Acérvulos; C. Acérvulo e setas; D. Conídios.

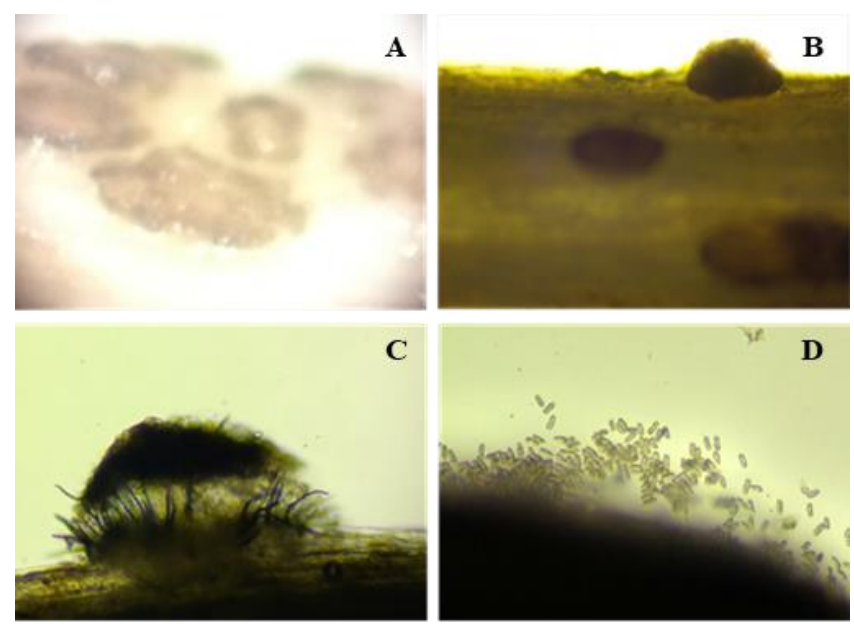

Contudo, o grau de sensibilidade foi diverso frente aos diferentes óleos essenciais. Entre os óleos essenciais testados, o fungo mostrou-se menos sensível aos óleos essenciais de tomilho-branco, mentaarvensis, citronela e melaleuca, com DHI entre 1,0 a 2,4 mm. Quanto aos outros óleos essenciais testados, foi obtida maior sensibilidade, destacando-se principalmente os óleos essenciais de canela-cássia e basilicão, que apresentaram um grande potencial de atividade antimicrobiana com diâmetros de halo de inibição que variaram de 9,9 a $8,1 \mathrm{~mm}$, respectivamente, se comportando próximo ao controle fungicida com 10,2 mm de halo de inibição. Seguidos pelos óleos essenciais de gengibre e laranja-doce, nos quais os diâmetros dos halos de inibição foram 5,0 e 4,9 $\mathrm{mm}$ respectivamente.

A CIM dos óleos essenciais de basilicão e canela-cássia contra C. gloeosporioides ficou em 5 $\mu \mathrm{L} / \mathrm{mL}$, para os óleos essenciais de gengibre, laranjadoce e melaleuca ficou em $20 \mu \mathrm{L} / \mathrm{mL}$ e para os demais óleos essenciais, $160 \mu \mathrm{L} / \mathrm{mL}$. 
Tabela 2. Halo de inibição, concentração inibitória mínima e concentração fungicida mínima de diferentes óleos essenciais contra Colletotrichum gloeosporioides.

\begin{tabular}{|c|c|c|c|c|c|c|}
\hline Óleo essencial & $\mathrm{DHI}^{1}$ & CIM $^{2}$ & $\mathrm{CFM}^{3}$ & $\mathrm{CF}^{4}$ & $\mathrm{CE}^{5}$ & $\mathrm{CC}^{6}$ \\
\hline Controle fungicida & 10,2 & n.v. ${ }^{7}$ & n.v. ${ }^{7}$ & - & - & + \\
\hline Basilicão & 8,1 & 5 & 160 & - & - & + \\
\hline Gengibre & 5,0 & 20 & 80 & - & - & + \\
\hline Laranja-doce & 4,9 & 20 & 160 & - & - & + \\
\hline Canela-cássia & 9,9 & 5 & 10 & - & - & + \\
\hline Melaleuca & 2,4 & 20 & $\mathrm{ND}^{*}$ & - & - & + \\
\hline Citronela & 1,6 & 160 & $\mathrm{ND}^{*}$ & - & - & + \\
\hline Menta-arvensis & 1,1 & 160 & $\mathrm{ND}^{*}$ & - & - & + \\
\hline Tomilho-branco & 1,0 & 160 & ND* & - & - & + \\
\hline
\end{tabular}

*Não detectado até a mais elevada concentração testada de $320 \mu \mathrm{L} / \mathrm{mL} ;{ }^{1}$ Diâmetro do halo de inibição (mm); ${ }^{2}$ Concentração inibitória mínima $(\mu \mathrm{L} / \mathrm{mL}) ;{ }^{3}$ Concentração fungicida mínima $(\mu \mathrm{L} / \mathrm{mL}) ;{ }^{4}$ Controle fungicida; ${ }^{5}$ Controle de esterilidade; ${ }^{6}$ Controle de crescimento; ${ }^{7} \mathrm{Não}$ verificado.

No presente estudo, a CFM foi determinada para os óleos essenciais de basilicão, gengibre, laranjadoce e canela-cássia, com $100 \%$ de inibição do crescimento micelial no subcultivo. Para os demais, não foi alcançada uma concentração fungicida mínima até a concentração máxima testada de $320 \mu \mathrm{L} / \mathrm{mL}$. Nesse caso, ficariam muito altas as concentrações e poderia não ser considerado efetivo como fungicida. Segundo Marinelli et al. (2012) para considerar a possibilidade de uso de um óleo essencial como biofuncigida o volume utilizado deve ser viável, devido ao alto custo e ainda, são necessários experimentos para verificar sua possível fitotoxicidade em condições de campo. Wuryatmo et al. (2003) enfatiza que aliado ao efeito fungicida contra o fitopatógeno, para considerar seu uso com eficácia, o óleo essencial não deve causar injúrias no fruto tratado e dependendo da sensibilidade do vegetal, pode se tornar tóxico em concentrações elevadas. Portanto os óleos essenciais de melaleuca, citronela, menta-arvensis e tomilho-branco se comportaram como fungistáticos e não fungicidas.
Quanto aos óleos essenciais que demonstraram tanto ação fungistática como fungicida (Figura 1) é importante ressaltar que, os óleos essenciais de basilicão e canela-cássia embora tenham a mesma CIM para C. gloeosporioides, a CFM foi bastante diversa. Canela-cássia foi o óleo essencial com a menor CFM obtida entre os óleos essenciais testados.

Figura 2. Óleos essenciais com sua concentração inibitória mínima (CIM) e concentração fungicida mínima (CFM) em $\mu \mathrm{L} / \mathrm{mL}$.

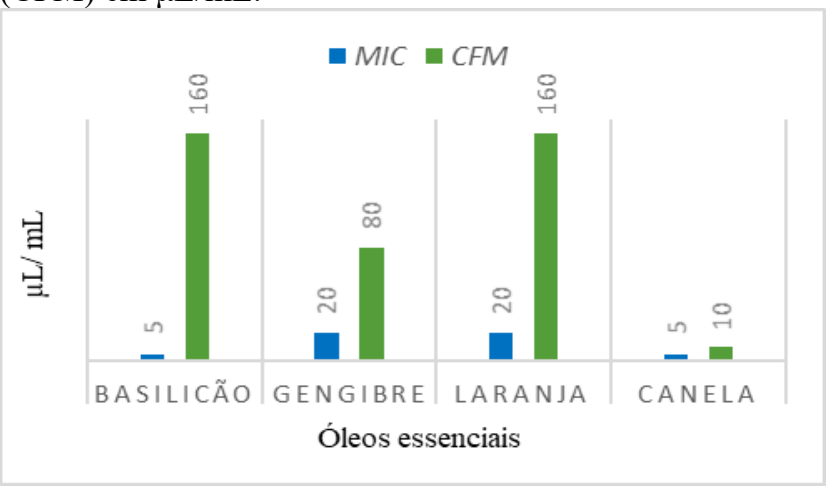

Similarmente, pesquisadores têm relatado o potencial desses óleos essenciais, como fungicida ou inibidor de diferentes microrganismos. Castro e Lima 
(2011) relataram expressivo potencial antifúngico de óleo essencial de basilicão sobre cepas de Candida albicans e C. tropicalis.

Em estudos para avaliação do efeito de extratos de gengibre, também foi possível evidenciar o efeito inibitório, sobre o crescimento micelial de Alternaria solani. Pedroso et al. (2009) utilizaram extrato de gengibre na concentração de $30 \%$ para controle de $A$. solani in vitro com redução de $40 \%$ o crescimento micelial.

O presente estudo corroborou com outras publicações citadas na literatura, em relação ao efeito inibidor $\mathrm{e}$ fungicida de gengibre sobre $C$. gloeosporioides. Rozwalka et al. (2008) evidenciaram o efeito inibitório de extratos de gengibre sobre o crescimento micelial de C. gloeosporioides, indicando o potencial desses extratos no controle da antracnose em frutos de goiabeira. Do mesmo modo, o efeito fungicida do óleo essencial de gengibre também foi citado em estudos mais recentes. A atividade antifúngica do óleo essencial de gengibre também foi avaliada em ensaios por Ali et al. (2016), no qual avaliaram a eficácia do óleo essencial de gengibre $(2,0 \%)$ e extrato $(1,5 \%)$ combinado com a goma arábica $(10,0 \%)$ no método de controle físico da antracnose e na qualidade de frutos de mamão durante $o$ armazenamento refrigerado. Os autores observaram que o óleo essencial de gengibre combinado com a goma arábica inibiu a germinação dos conídios de $C$. gloeosporioides (93\%), e afirmam que estes resultados demonstraram a eficácia deste biofungicida para o controle da antracnose na pós-colheita do mamão.

Rodrigues et al. (2018) determinaram a melhor concentração de diferentes óleos essenciais para controlar Colletotrichum musae e a intensidade da antracnose em banana 'Prata Anã. Os óleos de cravo e tomilho foram os mais eficientes na inibição do crescimento micelial, germinação e esporulação em todas as concentrações testadas (2 a $8 \mu \mathrm{L} /$ papel filtro).
Os óleos essenciais de melaleuca ( $240 \mu \mathrm{L} /$ papel filtro) e gengibre (160 $\mu \mathrm{L} /$ papel filtro) dispostos em recipientes de plástico contendo as frutas obtiveram a capacidade de suprimir a antracnose na banana 'Prata Anã', com a redução da incidência de antracnose em frutas em $48 \%$ e $24 \%$, respectivamente.

A atividade antifúngica do óleo essencial de laranja-doce obtido no atual estudo, também foi alcançada anteriormente por outros pesquisadores, inclusive para outros microrganismos, como em Gomes (2011) quando estudou a atividade antimicrobiana do óleo essencial de laranja-doce sobre os fitopatógenos Fusarium oxysporum, Alternaria alternata e C. musae, em que obteve fungitoxicidade para esses fungos testados.

Venturoso et al. (2011), testaram diferentes extratos contra fitopatógenos. Os autores citam a atividade antifúngica de extratos de casca de canela como eficazes em testes in vitro realizados sobre Cercospora kikuchii.

Ogbebor et al. (2007) determinaram as concentrações fungicidas mínimas para óleos essencias e extratos vegetais contra o fungo $C$. gloeosporioides. Entre os óleos essenciais utilizados que apresentaram atividade fungicida em diferentes concentrações, encontra-se de 0,80\% (melaleuca), 6,25\% (canela), $12,5 \%$ (citronela), $50 \%$ (gengibre) e $100 \%$ (manjericão), com grande eficácia nas reduções da contagem microbiana para o óleo essencial de melaleuca $(-99,2 \%)$.

Martins et al. (2011), verificaram que o óleo essencial de melaleuca in vitro reduziu o crescimento micelial dos fungos Macrophomina phaseolina, Sclerotinia sclerotiorum e A. alternata. Souza et al. (2015) avaliou o óleo essencial de melaleuca no controle da cercosporiose (Cercospora beticola) em beterraba, no qual a eficácia foi obtida in vivo e, como consequência, houve melhor desenvolvimento na produção de raízes. Na concentração de $1 \%$, a redução 
micelial foi de $99 \%$ e os índices de infecção de $20 \%$. Da mesma forma, o óleo essencial de melaleuca em diferentes estudos apresenta sua atividade fungicida. Ramos et al. (2016) avaliaram a atividade antifúngica de óleos essenciais e vegetais no controle in vitro de $C$. gloeosporioides e constataram a ação fungicida do óleo essencial de melaleuca na concentração inibitória mínima e a concentração fungicida mínima de $0,8 \%$.

A eficiência do óleo essencial de citronela também foi observada no controle de doenças fitopatogênicas. A atividade fungitóxica de citronela foi evidenciada nos estudos de Cruz et al. (2015), em que relatam uma inibição em mais de $90 \%$ da germinação de esporos e redução de mais de $95 \%$ da produção de esporos de Fusarium solani sobre placas com o óleo essencial na alíquota de $5 \mu \mathrm{L}$ na superfície do meio de cultura BDA. Assim como, a atividade antifúngica contra diversos fitopatógenos, tais como Fusarium solani, Aspergillus niger, Cladosporium sp. (ANDILA et al., 2018). Kalupahana et al. (2020) citam baixa atividade inibitória no controle da antracnose, causada por Colletotrichum siamense com o óleo essencial de citronela. No presente trabalho, o óleo essencial de citronela não apresentou atividade antifúngica sobre $C$. gloeosporioides nas concentrações testadas. Contudo, a CIM foi alcançada em $160 \mu \mathrm{L} / \mathrm{mL}$.

Gadelha et al. (2003), utilizaram uma mistura de óleos essenciais de menta-arvensis com alecrimpimenta, alfavaca, eucalipto e óleo fixo de soja, no tratamento do pedúnculo do melão 'Orange flesh' infectado artificialmente com Fusarium sp. O tratamento obteve eficácia com ação curativa e preventiva do Fusarium sp. e sua atividade foi atribuída ao óleo essencial de menta-arvensis na mistura, graças a presença de mentol, que se apresenta em $70 \%$ de sua constituição. Já Chagas et al. (2020) determinaram uma concentração maior ainda desse constituinte. Na caracterização do óleo essencial por cromatografia gasosa e espectrometria de massas (CG / EM) obteve a constituição de mentol em 86,1\%, sendo que a constituição do óleo essencial contém 97, 1\% de monoterpenos oxigenados.

Diferentes estudos fazem referência à ação fungistática e fungicida dos óleos essenciais devido a seus constituintes químicos. Romero et al. (2009) testaram o óleo essencial de tomilho quanto à sua atividade antifúngica in vivo sobre microrganismos fitopatogênicos de importância econômica: Myrothecium verrucaria, Corynespora cassiicola, Erwinia psidii, Sclerotinia minor e C. musae. A completa inibição dos microrganismos testados ocorreu na concentração 5 a $200 \mu \mathrm{L} / \mathrm{mL}$, sendo mais eficaz para o controle de $C$. musae $(5 \mu \mathrm{L} / \mathrm{mL}), S$. minor (10 $\mu \mathrm{L} / \mathrm{mL}), F$. moniliforme $(10 \mu \mathrm{L} / \mathrm{mL})$ e $C$. cassiicola $(15$ $\mu \mathrm{L} / \mathrm{mL}$ ). De acordo com Kerman (2012), as atividades antifúngicas do tomilho estão relacionadas ao elevado percentual do constituinte timol, um monoterpeno que é seu principal constituinte.

O composto eugenol e timol também se destacaram no controle da mancha foliar em maçã causada por C. fructicola (SCHORR, 2018). Do mesmo modo, foram testados como fungicidas para $F$. verticillioides e Rhizopus stolonifer. Foi observado um efeito sinérgico abaixo das concentrações de CIM para carvacrol (100 mg/L) e timol (100-375 mg/L). Foi estabelecida uma relação inversa entre a concentração antimicrobiana e o desenvolvimento micelial de ambos os fungos (OCHOA-VELASCO et al., 2018).

O componente majoritário quantificado com grande expressividade $(93,8 \%)$ no óleo essencial de canela-cássia no presente estudo é o (E)-Cinamaldeído, um composto ativo que tem sido amplamente utilizado com efeitos biológicos, farmacológicos e antimicrobianos (FIGUEIREDO et al., 2017). Xie et al. (2017) relataram boa atividade fungicida da canelacássia e seu principal composto químico, o cinamaldeído contra os fitopatógenos Rhizoctonia 
solani e $F$. oxysporum (IC50 = 106,5 e 149,9 $\mu \mathrm{g} / \mathrm{mL}$, respectivamente).

Os resultados do presente estudo corroboram com publicações citadas na literatura em relação ao efeito fungistático e/ ou fungicida dos óleos essenciais estudados. Verificou-se neste trabalho, que os óleos essenciais apresentaram potencial de uso no controle de C. cladosporioides, destacando-se os de gengibre e canela-cássia por alcançarem a mais baixa CFM. Ainda assim, estudos adicionais são fundamentais para identificar os compostos químicos bioativos e constatar a atividade fungicida, uma vez que $C$. gloeosporioides demonstrou sensibilidade a todos os óleos essenciais avaliados. Faz-se necessário, então, o desenvolvimento de metodologia segura para ensaios in vivo, ante a necessidade de produtos agrícolas naturais no manejo de fitopatógenos, com potencial de uso em uma viável higienização dos frutos em pós-colheita ou "packing house".

\section{CONCLUSÃO}

O fitopatógeno C. gloeosporioides apresentouse sensível aos óleos essenciais testados no presente estudo. A CIM inibiu o crescimento do fitopatógeno, sendo $o$ efeito diretamente proporcional à concentração. A atividade fungicida dos óleos essenciais de canela-cássia, gengibre, basilicão e laranja-doce foi comprovada mediante a determinação da CFM. Para os óleos essenciais de melaleuca, citronela, menta-arvensis e tomilho-branco não foi detectada ação fungicida nas concentrações testadas, estes demonstraram ação fungistática para $C$. gloeosporioides. Os resultados alcançados impulsionam estudos mais abrangentes, incluindo testes in vivo, na busca por elucidar os possíveis mecanismos de ação envolvidos nessas interações e ainda, indicar direções em contraposição ao uso abusivo de substâncias químicas sintéticas, que causam distúrbios e persistem nos ecossistemas.

\section{AGRADECIMENTO}

Os autores agradecem o apoio recebido da: Universidade Federal Rural do Rio de Janeiro (UFRRJ), Coordenação de Aperfeiçoamento de Pessoal de Nível Superior (CAPES) e Embrapa Agrobiologia.

Todos os autores declararam não haver qualquer potencial conflito de interesses referente a este artigo.

\section{REFERÊNCIAS}

ADAMS, R.P. Identification of essential oils components by gas chromatography/quadrupole mass spectroscopy. Carol Stream, Illinois, USA: Allured Publishing Corporation; 2007.

AGRIOS, George.N. Plant Pathology. 5. ed. San Diego, California, Elsevier Academic Press; 2005.

ALFENAS, A.C.; MAFIA, R.G. Métodos em fitopatologia. 1. ed. Viçosa, MG, UFV; 2007.

ALI, A.; HEI, G.K.; KEAT, Y.W. Efficacy of ginger oil and extract combined with gum arabic on anthracnose and quality of papaya fruit during cold storage. Journal of Food Science and Technology, v. 3, n. 1, p.1-10, 2016. Disponível em: https://dx.doi.org/10.1007\%2Fs13197-015-2124-5. Acesso em: 03/09/2020.

ANDILA, P.S.; HENDRA, I.P.A.; WARDANI, P.K.; TIRTA, I.G.; SUTOMO; FARDENAN, D. The phytochemistry of Cymbopogon winterianus essential oil from Lombok Island, Indonesia and its antifungal activity against phytopathogenic fungi. Nusantara Bioscience, v. 10, n. 4, p.232-239, 2018. Disponível em: https://doi.org/10.13057/nusbiosci/n100406. Acesso em: 03/09/2020.

ANVISA. 2019. Agência Nacional de Vigilância Sanitária. Programa de Análise de Resíduos de Agrotóxicos em Alimentos - PARA. Gerência geral de toxicologia, Brasília, 10 dez.

BALOUIRI, M.; SADIKI, M.; IBNSOUDA, S.A. Methods for in vitro evaluating antimicrobial activity: A review. Journal of Pharmaceutical Analysis, v. 6, n. 2, p.71-79, 2016. Disponível em: https://doi.org/10.1016/j.jpha.2015.11.005. Acesso em: 03/09/2020.

BARNETT, H.L.; HUNTER, B.B. Ilustrated genera of imperfect fungi. 4. ed. St. Paul (Minnesota), APS press; 1998.

CANNON, P.F., DAMM, U.; WEIR, B.S. Colletotrichum - current status and future directions. Studies in Mycology, v. 73, n. 1, p.181-213, 2012. 
CASTRO, R.D.; LIMA, E.O. Screening da Atividade Antifúngica de Óleos Essenciais. Pesquisa Brasileira Odontopediatria e Clínica Integrada, João Pessoa, v. 11, n. 3, p.341-5, 2011. Disponível em: https://www.redalyc.org/articulo.oa?id=637/63722164 006. Acesso em: 02/09/2020.

CHAGAS, E.C.; MAJOLO, C.; MONTEIRO, P.C.; OLIVEIRA, M.R.; GAMA, P.E.; BIZZO, H.R.; CHAVES, F.C. Composition of essential oils of Mentha species and their antimicrobial activity against Aeromonas spp. Journal of Essential Oil Research, v. 32, n. 3, p.209-215, 2020. Disponível em: https://doi.org/10.1080/10412905.2020.1741457.

Acesso em: 02/09/2020.

CHAVES, G.M.; CARVALHO, M.G.; CRUZ FILHO, J.; ROMEIRO, RS. Roteiro de aulas práticas de fitopatologia. Viçosa, UFV; 1973.

CLSI, Clinical and Laboratory Standards Institute. Methods for Dilution Antimicrobial Susceptibility Tests for Bacteria That Grow Aerobically. 9. ed. Wayne, Pennsylvania; 2012.

CRUZ, T.P.; ALVES, F.R.; MENDONÇA, R.F.; COSTA, A.V.; JESUS JUNIOR, W.C.; PINHEIRO, P.F.; MARINS, A.K. Atividade fungicida do óleo essencial de Cymbopogon winterianus JOWIT (citronela) contra Fusarium solani. Bioscience Journal, v. 31, n. 1, p.1-8, 2015. Disponível em: https://doi.org/10.14393/BJ-v31n1a2015-22346.

Acesso em: 02/09/2020.

DOMSCH, K.H.; GAMS, W.; ANDERSON, T.H. Compendium of soil Fungi. Vol 1. New York, Academic Press; 1980.

ESPINEL-INGROFF, A; FOTHERGILL, A.; PETER, J.; RINALDI, M.G.; WALSH, T.J. Testing conditions for determination of, minimum fungicidal concentrations of new and established antifungal agents for Aspergillus spp: NCCLS collaborative study. Journal of Clinical Microbiology, v. 40, n. 9, p.3204-3208, 2002. Disponível em: https://dx.doi.org/10.1128\%2FJCM.40.9.3204-

3208.2002. Acesso em: 03/09/2020.

FALEIRO, F.G.; JUNQUEIRA, N.T.V. Maracujá: o produtor pergunta, a Embrapa responde. Brasília, DF, Embrapa; 2016.

FIGUEIREDO, C.S.S.S.; OLIVEIRA, P.V.; SAMINEZ, W.F.S.; RODRIGUES, J.F.S.; SILVA, M.S.M.; SILVA, L.C.N.; GRISOTTO, M.A.G. Óleo essencial da Canela (Cinamaldeído) e suas aplicações biológicas, Revista de Investigação Biomédica, São Luís, v. 9, n. 2, p.192-197, 2017.

FISCHER, I.H.; KIMATI, H.; REZENDE, J.A.M. Doenças do maracujazeiro. In: KIMATI, H.;
AMORIM, L.; REZENDE, J.A.M.; BERGAMIN FILHO, A.; CAMARGO, L.E.A. (Eds.) Manual de Fitopatologia Agronômica. Ceres, São Paulo, Brasil, v.2, p.467-474; 2005.

GADELHA, J.C.; INNECCO, R.; ALCANFOR, D.C.; MATTOS, S.H.; MEDEIROS-FILHO, S.; VIEIRA, A.V. Defensivos naturais no tratamento pós-colheita de pedúnculos do melão. Revista Ciência Agronômica, v. 34, n. 1, p.5-10, 2003. Disponível em: file://C:/Users/anaro/Downloads/14rca34-1.pdf.

Acesso em: 02/09/2020.

GAHUKAR, R.T. Management of pests and diseases of important tropical/subtropical medicinal and aromatic plants: A review. Journal of Applied Research on Medicinal and Aromatic Plants, v. 9, p.1-18, 2018. Disponível em: https://doi.org/10.1016/j.jarmap.2018.03.002. Acesso em: 02/09/2020.

GOMES, M. S. Caracterização química e atividade antifúngica dos óleos essenciais de cinco espécies do gênero Citrus. 2011. 98p. Dissertação de mestrado UFLA, Lavras, 2011.

JEHL, F.; BONNET, R.; BRU, J.; CARON, F.; CATTOEN, C.; CATTOIR, V. Comite de L'antibiogramme de la societe française de microbiologie. Recommandations 2018. Ed. Paris, Société Française de Microbiologie; 2018.

JUNQUEIRA, N.T.V., ANSELMO, R.M., PINTO, A.C.Q., PEREIRA, A.V.; NASCIMENTO, A.C. Severidade da antracnose e perda de matéria fresca de frutos de dez procedências de maracujazeiro-doce (Passiflora alata Dryander) em dois ambientes de armazenamento. Revista Brasileira de Fruticultura, Jaboticabal-SP, v. 25, n. 1, p. 71-73, 2003. Disponível em: $\quad$ https://doi.org/10.1590/S010029452003000100021. Acesso em: 27/08/2020.

JUNQUEIRA, N.T.V.; GUIMARÃES, T.G. Manejo das principais doenças da goiabeira. In: Núcleo de Estudos em Fitopatologia (Org.). Manejo integrado de doenças em fruteiras. Brasília, DF, Sociedade Brasileira de Fitopatologia; 2007.

KALUPAHANA， K. I. M.; KURUPPU, M.; DISSANAYAKE, P. K. Effect of Essential Oils and GRAS Compounds on Postharvest Disease Control in Mango (Mangifera indica L.cv Tom EJC). The Journal of Agricultural Sciences, v. 15, 2020, p.207221. Disponível em: http://doi.org/10.4038/jas.v15i2.8802. Acesso em: 02/09/2020.

KERMAN, I. Antifungal effects of the essential oil from Thymus vulgaris L. and comparison with synthetic thymol on Aspergillus niger. Journal of Yeast and Fungal Research, v. 3, n. 6, p.83 - 88, 2012. Disponível 
http://www.academicjournals.org/JYF. Acesso em: 02/09/2020.

MARINELLI, E.; ORZALI, L.; LOTTI, E.; RICCIONI, L. Activity of Some Essential Oils against Pathogenic Seed Borne Fungi on Legumes. Asian Journal of Plant Pathology, v. 6, n. 3, p.6674, 2012. Disponível em: http://dx.doi.org/10.3923/ajppaj.2012.66.74. Acesso em: 03/09/2020.

MARTINS, J.A.S.; SAGATA, E.; SANTOS, V.A.; CEZAR, J.F. Avaliação do efeito do óleo de Melaleuca alternifolia sobre o crescimento micelial in vitro de fungos fitopatogênicos. Bioscience Journal (Online), v. 27, n. 1, p.49-51, 2011. Disponível em: https://www.researchgate.net/publication/277029587. Acesso em: 03/09/2020.

BRASIL. MINISTÉRIO DA SAÚDE. 2017. Resolução No 185 , de 18 de outubro de 2017. Dispõe sobre a proibição do ingredienteativo Carbofurano em produtos agrotóxicos no país e sobre as medidas transitórias de descontinuação de seu uso nas culturas de banana, café e cana-de-açúcar. DIÁRIO OFICIAL DA UNIÂA, 19 out.

MOUTASSEM, D.; BELABID, L.; BELLIK, Y.; ZIOUCHE, S; BAALI, F. Efficacy of essential oils of various aromatic plants in the biocontrol of Fusarium wilt and inducing systemic resistance in chickpea seedlings. Plant Protection Science, v. 55, n. 3, p.202-217, 2019. Disponível em: https://www.researchgate.net/deref/http $\% 3 \mathrm{~A} \% 2 \mathrm{~F} \% 2 \mathrm{~F}$ dx.doi.org\%2F10.17221\%2F134\%2F2018-PPS.

Acesso em: 02/09/2020.

OCHOA-VELASCO, C.E., NAVARRO-CRUZ, A., VERA-LÓPEZ, O., PALOU, E.; AVILA-SOSA, R. Growth modeling to control (in vitro) Fusarium verticillioides and Rhizopus stolonifer with thymol and carvacrol. Revista Argentina de Microbiología, v. 50, n. 1 , p.70-74, 2018. Disponível em: https://doi.org/10.1016/j.ram.2016.11.010. Acesso em: 02/09/2020.

OGBEBOR, N.O., ADEKUNLE, A.T.; ENOBAKHARE, D.A. Inhibition of Colletotrichum gloeosporioides (Penz) Sac. causal organism of rubber (Hevea brasiliensis Muell. Arg.) leaf spot using plant extracts. African Journal of Biotechnology, v. 6, n. 3, p.213-218, 2007. Disponível em: http://www.academicjournals.org/AJB. Acesso em: 02/09/2020.

PEDROSO, D.; MENEZES, V.; JUNGES, E.; MULLER, J.; GIRARDI, L.; DILL, A.; MUNIZ, M. e BLUME, E. Potencial Inibitório in vitro de Alternaria solani Sob Efeito de Extratos Botânicos. Revista Brasileira de Agroecologia, v. 4, n. 2, p.4260-4263, 2009.
PEREIRA, F.O.; WANDERLEY, P.A.; VIANA, F.A.C.; LIMA, R.B.; SOUSA, F.B., LIMA, E.O. Growth inhibition and morphological alterations of Trichophyton rubrum induced by essential oil from Cymbopogon winterianus Jowitt ex bor. Brazilian Journal of Microbiology, v. 42, n. 1, p.233-242, 2011. Disponível em: https://doi.org/10.1590/S151783822011000100029. Acesso em: 02/09/2020.

RAMOS, K.; ANDREANI JUNIOR, R.; KOZUSNYANDREANI, D.I. Óleos essenciais e vegetais no controle in vitro de Colletotrichum gloeosporioides. Revista Brasileira de Plantas Medicinais, v. 18, n. 2, supl. I, p.605-612, 2016. Disponível em: https://doi.org/10.1590/1983-084x/15_192. Acesso em: 02/09/2020.

RODRIGUES, M.L.M.; MIZOBUTSI, E.H.; NACARATH, I.R.F.F.; FERNANDES, M.B.; MIZOBUTSI, G.P.; RIBEIRO, R.C.F; REIS, S.T.; PINHEIRO, J.M.S.; PRATES, P.J.L.; LAGE, G.G.A. Essential Oils in the Control of Anthracnose on 'Prata Ana' Banana. Journal of Agricultural Science, v. 10, n. 9, p.116-124, 2018. Disponível em: https://doi.org/10.5539/jas.v10n9p116. Acesso em: 02/09/2020.

ROMERO, A.L.; SPECIAN, V.; OLIVEIRA, R.C.; DINIZ, S.P.S.S. Atividade do Óleo Essencial de Tomilho (Thymus vulgaris L.) Contra Fungos Fitopatogênicos. UNOPAR Científica. Ciências biológicas e da saúde, v. 11, n. 4, p.15-8, 2009. Disponível file://C:/Users/anaro/Downloads/1426-

Texto\%20do\%20artigo-5496-1-10-

20150706\%20(1).pdf. Acesso em: 02/09/2020.

ROZWALKA, L.C.; LIMA, M.L.R.Z.C; MIO, L.L.M.; NAKASHIMA, T. Extratos, decoctos e óleos essenciais de plantas medicinais e aromáticas na inibição de Glomerella cingulata e Colletotrichum gloeosporioides de frutos de goiaba. Ciência Rural, v. 38, n. 2, p.301-307, 2008. Disponível em: https://doi.org/10.1590/S0103-84782008000200001. Acesso em: 02/09/2020.

SCHORR, R.R. Estudos visando o desenvolvimento de novo fungicida como alternativa de controle de fitopatógenos da maçã baseada em substâncias de baixa toxidade. 2018 . 94p. Dissertação de mestrado Universidade Federal do Paraná - UFPR, Curitiba, PR, 2018.

SHARMA A., Rajendran S., Srivastava, A., Sharma, S., Kundu, B. Antifungal activities of selected essential oils against Fusarium oxysporum f. sp. lycopersici 1322, with emphasis on Syzygium aromaticum essential oil. Journal of Bioscience and Bioengineering, v. 123, n. 3, p.308-313, 2017. Disponível em: https://doi.org/10.1016/j.jbiosc.2016.09.011. Acesso em: 27/08/2020. 
VENTUROSO, L. R.; BACCHI, L. M. A.; GAVASSONI, W. L.; CONUS, L. A.; PONTIM, B. C. A.; Bergamin, A. C. Atividade antifúngica de extratos vegetais sobre o desenvolvimento de fitopatógenos.

Summa Phytopathologica, v. 37, n. 1, p.18-23, 2011. Disponível em: https://doi.org/10.1590/S010054052011000100003. Acesso em: 02/09/2020.

WURYATMO, E.; KLIEBER, A.; SCOTT, E.S. Enhibition of citrus postharvest pathogens by vapor of citral and related compounds in culture. Journal of Agricultural and Food Chemistry, v. 51, n. 9, p.2637-2640, 2003. Disponível em: https://doi.org/10.1021/jf0261831. Acesso em: 05/11/2020.

XIE, Y.; HUANG, Q.; WANG, Z.; CAO, H.; ZHANG, D. Structure-activity relationships of cinnamaldehyde and eugenol derivatives against plant pathogenic fungi. Industrial Crops and Products, v. 97, p.388-394, $2017 . \quad$ Disponível em: https://doi.org/10.1016/j.indcrop.2016.12.043. Acesso em: 05/11/2020. 